\title{
Interactive comment on "Assessment of relative importance of debris flow disaster risk affecting factors based on meta-analysis - cases study of northwest and southwest China" by Yuzheng Wang et al.
}

\section{Anonymous Referee \#1}

Received and published: 29 January 2020

I think the manuscript may be resubmitted to NHESS after re-writing. Instead of a scientific paper, presently the manuscript looks like a technical report short of enough analysis in-depth. Writing problems exist throughout the manuscript. For examples (not all): 1. The abstract looks like that of a review paper. No any quantitative result and in depth analysis is found. I also can not found any quantitative result in the section "6. Conclusions". 2. Figures 1-2 are strange and unreadable. Furthermore, they look very similar. Why do not you merge them after a major revision? Please check other figures, e.g., Figs. 3-13. 3. Tables 1-3 seem very similar. Instead of the original data,

Printer-friendly version

Discussion paper 
might you sum up any common regularity from the three tables? Please check other tables.

NHESSD

Interactive comment on Nat. Hazards Earth Syst. Sci. Discuss., https://doi.org/10.5194/nhess2019-339, 2020.

Interactive

comment 